\title{
Testing the use of a citronella-based repellent as an effective method to reduce the prevalence and abundance of biting flies in avian nests
}

\author{
Josué Martínez-de la Puente \& Santiago Merino \& \\ Elisa Lobato \& Juan Rivero-de Aguilar \& \\ Sara del Cerro \& Rafael Ruiz-de-Castañeda
}

\begin{abstract}
Here, we validate the use of a citronella (natural oil) based repellent to reduce the abundance of flying blood-sucking insects in avian nests. These insects are important parasites of birds affecting them as blood feeders and as vectors of a diversity of pathogens. When nestling were 10 days old, we assigned wild great tit Parus major nests to one of two treatments, control and fumigated nests. The abundance of biting midges and blackflies captured during 3 days following the treatment application were lower in fumigated nests with respect to control ones. By contrast, the abundance of blowfly pupae measured when nestlings left their nests was not affected by the treatment. Although many experimental studies modify the abundance of nest-dweller ectoparasites, to our knowledge, this is the first one describing an easy, safe, and effective method, reducing the total abundance of both biting midges and blackflies in wild avian nests. Our results could be used in future conservation projects and experimental studies on host-parasite evolution affecting the abundance of flying blood-feeder insects under natural conditions.
\end{abstract}

\section{Introduction}

To date, the adverse effects of nest-dweller ectoparasites, including mites, bugs, fleas, and blowflies, on avian species have been widely investigated in many experimental and

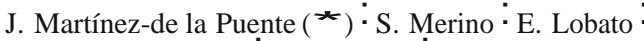

J. Rivero-de Aguilar ${ }^{\circ}$ S. del Cerro $*$ R. Ruiz-de-Castañeda

Departamento de Ecología Evolutiva,

Museo Nacional de Ciencias Naturales (CSIC),

J. Gutiérrez Abascal 2, 28006 Madrid, Spain

e-mail: jmp@mncn.csic.es correlative studies (Lehmann 1993; Loye and Carroll 1995; Merino and Potti 1998; Tomás et al. 2007; Lobato et al. 2008). By contrast, the relationships between flying bloodsucking insects and breeding birds under natural conditions have received scant attention in the literature.

Biting midges (Diptera: Ceratopogonidae) and blackflies (Diptera: Simuliidae) are two of the most important flying blood-feeder insects affecting birds. These insects are vectors of different pathogens such as viruses (Mellor et al. 2000) and parasites, including avian malaria-like parasites (Fallis and Bennett 1958; Bennett 1961; Atkinson et al. 1983). The combined effects of physical harassment, blood parasite infection, and loss of blood produced by these biting flies may affect birds in terms of condition (Tomás et al. 2008b), survival probability (Hunter et al. 1997; Smith et al. 1998), and reproductive success (Bukaciński and Bukaciński 2000), supporting their potential importance affecting the conservation of endangered species (Adler et al. 2007). However, to our knowledge, all of these studies are correlative, probably due to the absence of an effective method to carry out experimental modifications of the abundance of these insects in avian nests. Previously, the fumigation treatment of blue tit Cyanistes caeruleus nests with an insecticide solution comprising $0.5 \%$ permethrin and $1 \%$ piperonyl butoxide did not affect the total abundance of biting midges (Tomás et al. 2008a), although it was effective reducing the abundance of biting midge Culicoides engorged females (females with a recent blood meal in their abdomen; Martínez-de la Puente et al. submitted). In this context, the use of insect repellents could be an effective alternative to the use of insecticides. Commercially available insect repellents can be divided into two main categories, synthetic chemicals and plantderived essential oils. Citronella is a natural repellent 
derived from Cymbopogon grass containing several active ingredients, including terpines, alcohols, and aldehydes (Novak and Gerberg 2005). The insecticidal properties of this oil were discovered in 1901, and it was used for a time as a hair dressing for the control of fleas and lice (Peterson and Coats 2001). Insect repellents may reduce the probability of contact between insects and their hosts by a number of physiological or biochemical events, including the blocking of insects receptors and therefore their capacity of host location (Peterson and Coats 2001). Several factors may affect the efficacy of each repellent, including composition, the mode of application, and the insect species involved in each study, probably determining, at least in part, the contradictory results found in studies on the efficacy of plant-derived repellents (i.e., Trigg and Hill 1996; Braverman et al. 1999). The main aim of the present study is to evaluate the efficacy of a citronella-based repellent product against flying bloodsucking diptera in wild avian nests.

\section{Materials and methods}

Our study was carried out during the spring of 2008 in a population of great tits Parus major breeding in nest boxes in a Pyrenean oak Quercus pyrenaica forest located in Valsaín (Segovia, Central Spain, 40 53' $74 \mathrm{~N}, 4^{\circ} 01^{\prime} \mathrm{W}$, $1,200 \mathrm{~m}$ a.s.l.). Wooden nest boxes were hanging from branches at about $4 \mathrm{~m}$ above the ground. Periodical visits in the course of the breeding season allowed us to record hatching date and brood size of each nest. To capture flying insects, we placed inside and close to the roof of each nest box a plastic Petri dish with a thinly spread layer of body gel oil following the method described and tested by Tomás et al. (2008a). Petri dishes were placed in nest boxes when nestlings were 10 days old. At that moment, nests of similar hatching date and brood size were assigned to one of the two different treatments, control and fumigated nests. The treatment consisted of a unique application of the "Dixie Repellent Culicoides" (Química de Munguía S.A.-Quimunsa) containing water and excipients (inactive substances used as carriers of active ingredients), $96^{\circ}$ alcohol (35\%), citronella (3\%), and etil butilacetilaminopropionate (20\%). The same methodology was employed in control nests using water instead of the citronella repellent. According to the instructions, the product is ready to use by its application on the skin of several mammal species. Unfortunately, there is no information available for its application on avian species. To avoid any damages to nestling birds, they were extracted from nests prior to the repellent application and immediately left again in the nest. Three days later, Petri dishes were removed from nest boxes, and the number of nestlings in each nest was recorded. In the laboratory, we quantified the abundance of biting midges and blackflies collected in Petri dishes under a binocular lens (Motic K700; ×46.5 magnification). When nestlings left their nests, we searched each nest to quantify the abundance of blowfly Protocalliphora pupae.

Statistical analyses were conducted by using nonparametric tests (Statistica version 6.0, StatSoft, 2001). We employed Mann-Whitney U test for comparing two independent groups to check for differences in hatching date and brood size between experimental groups. In addition, the same procedure was employed to investigate the effect of the treatment affecting the total abundance of biting midges, blackflies, and blowflies. Chi-squared tests were employed to investigate the effect of the treatment on insect prevalences and on nestling mortality.

\section{Results}

A total of 30 nests were included in this study: 16 of them were treated as controls, and 14 were fumigated with the citronella-based repellent. As expected according to the design of the experiment, we did not find any significant differences in hatching date $(Z$-adjusted $=0.13 ; \mathrm{P}=0.90$ ) nor in brood size ( $\mathrm{Z}$-adjusted $=-0.37 ; \mathrm{P}=0.71$ ) between groups.

A higher prevalence of infection by biting midges were found in control (88\%) than in citronella-fumigated nests (21\%; Yates-corrected $X^{2}=10.72, P=0.001$ ). Also, the abundance of biting midges captured in avian nests was significantly reduced by the treatment (Fig. 1a; Z-adjusted= -3.09; $\mathrm{P}=0.002)$. The abundance of blackflies was also reduced by the treatment (Fig. $1 \mathrm{~b}$; Z-adjusted=-2.14; $\mathrm{P}=$ 0.03) with a higher, but not statistically significant, prevalence of infection found in control nests (69\%) than in citronella-fumigated nests (36\%; Yates-corrected $\mathrm{X}^{2}=$ 2.08, $\mathrm{P}=0.15)$. The treatment did not significantly affect the prevalence of infection by blowflies (fumigated nests $71 \%$, control nests $38 \%$, Yates-corrected $X^{2}=2.22, \mathrm{P}=0.14$ ). The abundance of blowfly pupae did not differ significantly between control and citronella-fumigated nests (Z-adjusted= 1.23; $\mathrm{P}=0.22$ ).

Finally, we did not find any significant effect of the treatment application on nestling mortality (Yates-corrected $\mathrm{X}^{2}=0.08, \mathrm{P}=0.78$ ) with only three control and three fumigated nests suffering the mortality of one nestling after the treatment application.

\section{Discussion}

Olfaction plays a key role in host location by vectors (Sutcliffe 1986; Bowen 1991), which are attracted to a diversity of body host odors (Fallis and Smith 1964; Blackwell et al. 1996). Repellents may affect the probabil- 


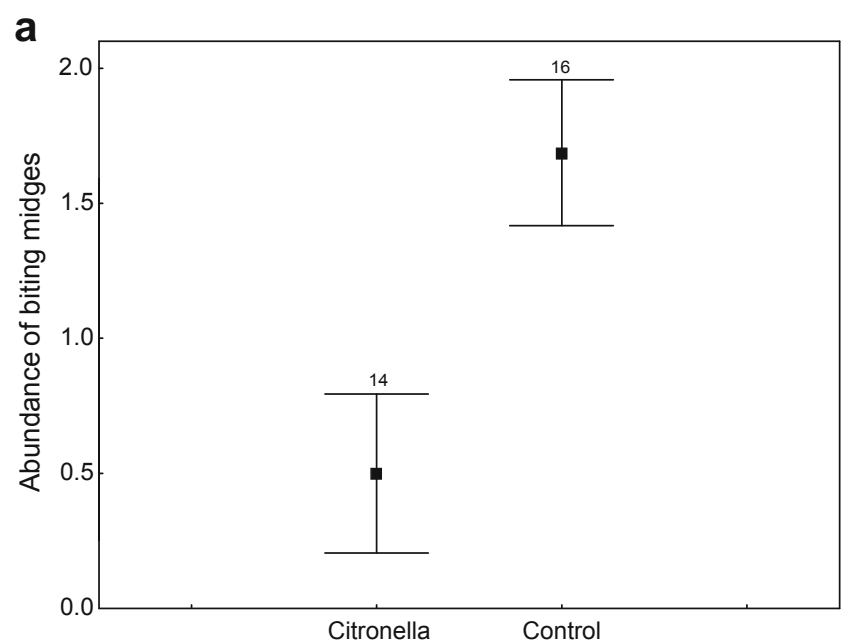

b

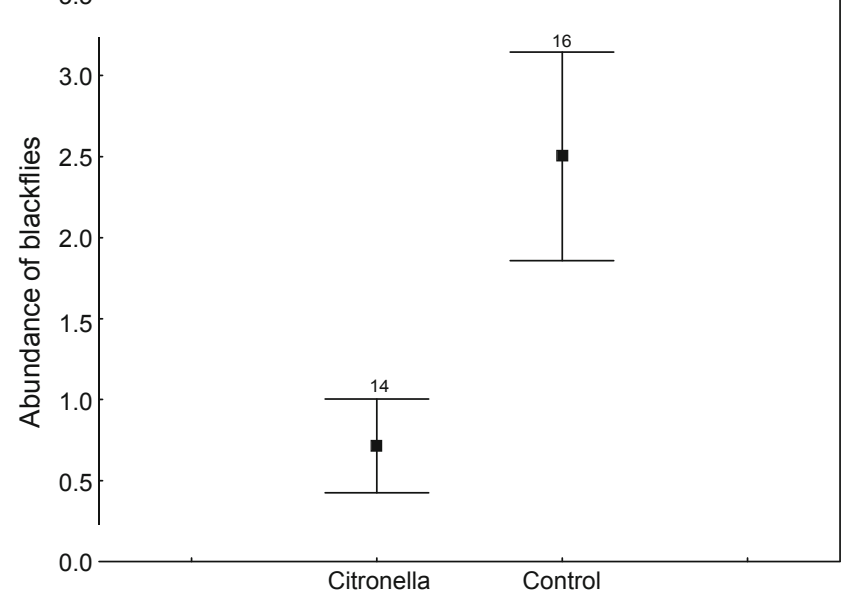

Fig. 1 Average abundance of biting midges (a) and blackflies (b) in great tit P. major nests with respect to the treatment with a citronellabased repellent. Bars denote standard errors

ity of contact between vectors and hosts by blocking insect receptors and therefore reducing their host location capacity (Peterson and Coats 2001). Citronella or citronella-derived components as insect repellents have been used since far (Peterson and Coats 2001) with reports of their repellent activity against different arthropods (Lindsay et al. 1996; Fradin and Day 2002; Barnard and Xue 2004; Kim et al. 2005; Amer and Mehlhorn 2006), although their efficacy varies between studies. Our results support the efficacy of this plant-derived repellent as an effective method to reduce the abundance of biting midges Culicoides and blackflies in wild avian nests. To date, many ornithological and parasitological studies have used insecticides to carry out experimental modifications of the abundance of nestdweller ectoparasites in avian nests (i.e., Merino and Potti 1998; Merino et al. 1999; Tomás et al. 2007; Lobato et al. 2008); however, this procedure may not be an effective method to reduce the total abundance of flying blood-feeder insects (see Tomás et al. 2008a).
The repellence efficacy of a product may be affected by different factors including the concentration of the active component (Lee et al. 2004; Kim et al. 2005) and the time since its application (i.e., Trigg and Hill 1996). Previous studies reported that oil of citronella could be effective for 4 h or even overnight (Brown and Hebert 1997). According to the instructions of the product employed here, the repellent remains effective during $8 \mathrm{~h}$ on species of livestock, including cattle, horses, sheep, goats, pigs, and other mammals. Our results support that nests impregnated with this product could maintain some degree of repellency for a longer period, reducing both the prevalence and abundance of biting midges and the abundance of blackflies in wild avian nests. The longer treatment efficacy reported here could be explained, at least in part, because in our study, the product was fumigated inside of each nest box, probably reducing the product evaporation with respect to its use on the skin of mammals. In fact, the repellent odor was still clearly perceptible when we opened nest boxes to remove Petri dishes, 3 days after the repellent application (per. obs.).

On the other hand, our results support that both the prevalence and abundance of infection by blowflies were not affected by the treatment. It is known that insects may differ in their sensitivity to repellents (Peterson and Coats 2001), suggesting the possibility of a differential efficacy of the treatment on blowflies with respect to both biting midges and blackflies. Furthermore, life cycle differences between biting flies (biting midges and blackflies) and blowflies could also affect the differential efficacy of the treatment. While adult females of both biting midges and blackflies feed blood, blowflies are ectoparasites of birds only during their larval stage (Lehane 2005). In this respect, it could be possible that blowflies infected nests in a moment prior to the treatment application (Bennett and Whitworth 1991), being not affected by the repellent. Finally, the differential efficacy of the treatment between biting flies and blowflies could be also due to methodological differences on parasite quantifications. While biting midges and blackflies were captured during the 3 days following the repellent application, the abundance of blowfly pupae was quantified several days later, when the efficacy of the treatment should be reduced.

In conclusion, here we present an effective method to reduce the abundance of biting flies in wild avian nests. These results could be useful studying host-parasite evolution by the experimental manipulation of the abundance of both biting midges and blackflies in avian nests. In addition, these results could be used in conservation programs of endangered avian species, which may suffer the adverse effects produced by biting flies and their parasites transmitted (Adler et al. 2007), probably affecting them in terms of condition, survival, and reproductive 
success (Hunter et al. 1997; Smith et al. 1998; Bukaciński and Bukaciński 2000; Tomás et al. 2008b). In this respect, although we have not detected any evidence of the treatment affecting the predation susceptibility of fumigated nests, further studies under differential predation pressures should be done to avoid the possibility that the odors from this treatment could increase nestling conspicuity to mammal or avian predators.

Acknowledgments We thank Javier Donés (Director of "Montes de Valsaín") for permission to work in the study area. The Junta de Castilla y León authorized the ringing and handling of birds.

This study was developed at the "El Ventorrillo" field station and funded by projects CGL2006-14129-C02-01 from the Ministerio de Educación y Ciencia and CGL2007-61251. J.M.P. is supported by a grant from the "El Ventorrillo". S.C. and R.R.C. were supported by a grant from the Comunidad de Madrid and a JAE-CSIC grant, respectively. J.M.P. also thanks members of the Animal Science Unit of the LPGC University for their help during the redaction of the manuscript.

\section{References}

Adler PH, Roach D, Reeves WK, Flanagan JP, Morrow ME, Toepfer JE (2007) Attacks on the endangered attwater's prairie-chicken (Tympanuchus cupido attwateri) by black flies (Diptera: Simuliidae) infected with an avian blood parasite. J Vector Ecol 32:309-312

Amer A, Mehlhorn H (2006) Repellency effect of forty-one essential oils against Aedes, Anopheles, and Culex mosquitoes. Parasitol Res 99:478-490

Atkinson T, Greiner EC, Forrester D (1983) Experimental vectors of Haemoproteus meleagridis Levine from wild turkeys in Florida. J Wildl Dis 19:366-568

Barnard DR, Xue R-D (2004) Laboratory evaluation of mosquito repellents against Aedes albopictus, Culex nigripalpus, and Ochlerotatus triseriatus (Diptera: Culicidae). J Med Entomol 41:726-730

Bennett GF (1961) On the specificity and transmission of some avian trypanosomes. Can J Zool 39:17-33

Bennett GF, Whitworth TL (1991) Studies on the life history of some species of Protocalliphora (Diptera: Calliphoridae). Can J Zool 69:2048-2058

Blackwell A, Dyer C, Mordue (Luntz) AJ, Wadhams LJ, Mordue W (1996) The role of 1-octen-3-ol as a host-odour attractant for the biting midge, Culicoides impunctatus Goetghebuer, and interactions of 1-octen-3-ol with a volatile pheromone produced by parous female midges. Physiol Entomol 21:15-19.

Bowen MF (1991) The sensory physiology of host-seeking behaviour in mosquitoes. Ann Rev Entomol 36:139-158

Braverman Y, Chizov-Ginzburg A, Mullens BA (1999) Mosquito repellent attracts Culicoides imicola (Diptera: Ceratopogonidae). J Med Entomol 36:113-115

Brown M, Hebert AA (1997) Insect repellents: an overview. J Am Acad Dermatol 36:243-249

Bukaciński D, Bukaciński M (2000) The impact of mass outbreaks of black flies (Simuliidae) on the parental behaviour and breeding output of colonial common gulls (Larus canus). Ann Zool Fennici 37:43-49

Fallis AM, Bennett GF (1958) Transmission of Leucocytozoon bonasae Clarke to ruffed grouse (Bonasa umbellus L.) by the black flies Simulium latipes MG. and Simulium aureum Fries. Can J Zool 36:533-539

Fallis AM, Smith SM (1964) Ether extracts from birds and $\mathrm{CO}_{2}$ as attractants for some ornithophilic simuliids. Can J Zool 42:723730

Fradin MS, Day JF (2002) Comparative efficacy of insect repellents against mosquito bites. N Engl J Med 347:13-18

Hunter DB, Rohner C, Curie DC (1997) Mortality in fledgling great horned owls from black fly hemathophaga and leucocytozoonosis. J Wildl Dis 33:486-491

Kim J-K, Kang C-S, Lee J-K, Kim Y-R, Han H-Y, Yun HK (2005) Evaluation of repellency effect of two natural aroma mosquito repellent compounds, citronella and citronellal. Entomol Res 35:117-120

Lee WJ, Lee HS, Ahn YJ, Lee DK (2004) Laboratory evaluation of controlled-release repellent treated pulp fabric on human volunteers against mosquito vectors. Entomol Res 34:37-42

Lehmann T (1993) Ectoparasites: direct impact on host fitness. Parasitol Today 9:8-13

Lehane M (2005) The biology of blood-sucking in insects, 2nd edn. Cambridge University Press, Cambridge

Lindsay LR, Surgeoner GA, Heal JD, Gallivan GJ (1996) Evaluation of the efficacy of 3\% citronella candles and 5\% citronella incense for protection against field populations of Aedes mosquitoes. J Am Mosq Control Assoc 12:293-294

Lobato E, Merino S, Moreno J, Morales J, Tomás G, Martínez-de la Puente J, Osorno JL, Kuchar A, Möstl E (2008) Corticosterone metabolites in blue tit and pied flycatcher droppings: effects of brood size, ectoparasites and temperature. Horm Behav 53:295-305

Loye J, Carroll S (1995) Birds, bugs and blood: avian parasitism and conservation. Trends Ecol Evol 10:232-235

Martínez-de la Puente J, Merino S, Tomás G, Moreno J, Morales J, Lobato E, Talavera S, Sarto i Monteys V (submitted) Factors affecting Culicoides species composition and abundance in avian nests

Mellor PS, Boorman J, Baylis M (2000) Culicoides biting midges: their role as arbovirus vectors. Ann Rev Entomol 45:307-340

Merino S, Potti J (1998) Growth, nutrition and blowfly parasitism in nestling pied flycatchers. Can J Zool 76:936-941

Merino S, Minguez E, Belliure B (1999) Ectoparasite effects on nestling European storm-petrels. Waterbirds 22:297-301

Novak RJ, Gerberg EJ (2005) Natural-based repellent products: efficacy for military and general public uses. J Am Mosq Control Assoc 21:7-11

Peterson C, Coats J (2001) Insect repellents—past, present and future. Pesticide Outlook 12:154-158

Smith RN, Cain SL, Anderson SH, Dunk JR, Williams S (1998) Blackfly-induced mortality of nestling red-tailed hawks. Auk 115:368-375

Sutcliffe JF (1986) Black fly host location: a review. Can J Zool 64:1041-1053

Tomás G, Merino S, Moreno J, Morales J (2007) Consequences of nest reuse for parasite burden and female health and condition in blue tits, Cyanistes caeruleus. Anim Behav 73:805-814

Tomás G, Merino S, Martínez-de la Puente J, Moreno J, Morales J, Lobato E (2008a) A simple trapping method to estimate abundances of blood-sucking flying insects in avian nests. Anim Behav 75:723-729

Tomás G, Merino S, Martínez-de la Puente J, Moreno J, Morales J, Lobato E (2008b) Determinants of abundance and effects of blood-sucking flying insects in the nest of a hole-nesting bird. Oecologia 156:305-312

Trigg JK, Hill N (1996) Laboratory evaluation of a eucalyptus-based repellent against four biting arthropods. Phytotherapy Res 10:313-316 